\title{
Wymiar fraktalny gradientowej warstwy pośredniej $\mathrm{Al}_{2} \mathrm{O}_{3}-\mathrm{Cr}$
}

\section{The fractal dimension of $\mathrm{Al}_{2} \mathrm{O}_{3}-\mathrm{Cr}$ graded intermediate layers}

\section{Streszczenie}

W artykule przedstawiono wyniki pomiarów wymiaru fraktalnego struktury gradientowej warstwy pośredniej w złączu $\mathrm{Al}_{2} \mathrm{O}_{3}-\mathrm{H} 25 \mathrm{~T}$. Dla analizowanych struktur warstwy pośredniej określono zawartość $\mathrm{Al}_{2} \mathrm{O}_{3}$ oraz wymiar fraktalny liniowy, wykorzystując metodę linii pomiarowej (LCD), będącą modyfikacją metody box counting dimension (BCD).

\section{Wstęp}

W złączach ceramiczno - metalowych istotnym problemem są naprężenia własne generowane w czasie procesu spajania. Ich główną przyczyną są znaczne różnice we właściwościach łączonych materiałów, takich jak współczynnik rozszerzalności liniowej i moduł sprężystości podłużnej. W celu uniknięcia zbyt wysokiego poziomu naprężeń w złączu i ich niekorzystnego rozkładu stosuje się różne konstrukcyjne i technologiczne sposoby, m.in. zmiany konstrukcyjne w złączu (zmiana wymiarów i kształtu elementów łączonych) oraz przekładki kompensacyjne o określonych właściwościach. Jednym z rodzajów takich przekładek są przekładki wielowarstwowe $\mathrm{z}$ gradientem właściwości (FGM).

W artykule zamieszczono wyniki pomiarów wymiaru fraktalnego struktury poszczególnych warstw składających się na materiał gradientowy, stanowiący warstwę pośrednią w złączu ceramiki korundowej $\mathrm{Al}_{2} \mathrm{O}_{3}$ ze stalą H25T.

Dr inż. Jarosław Grześ - Politechnika Warszawska.

\section{Abstract}

The paper presents the results of $\mathrm{Al}_{2} \mathrm{O}_{3}-\mathrm{Cr}$ FGM intermediate layer fractal analysis. The intermediate layers were used to obtain the $\mathrm{Al}_{2} \mathrm{O}_{3}-\mathrm{H} 25 \mathrm{~T}$ joints. The selected cross-section structures of $\mathrm{Al}_{2} \mathrm{O}_{3}-\mathrm{Cr}$ intermediate layer have been the subject of investigation. The computer image processing techniques have been applied to prepare binary images of structures for $\mathrm{Al}_{2} \mathrm{O}_{3}$ distribution and fractal dimension measurements. The line counting dimension algorithm, based on the box counting dimension method (BCD), has been used to obtain the fractal dimension of analyzed structures.

\section{Przedmiot i metodyka badań}

Przedmiot badań stanowiła warstwa pośrednia w złączu ceramiki korundowej $\mathrm{Al}_{2} \mathrm{O}_{3}$ ze stalą $\mathrm{H} 25 \mathrm{~T}$, składająca się $\mathrm{z}$ mieszaniny proszku $\mathrm{Al}_{2} \mathrm{O}_{3}$ (wielkość ziarna $80 \mu \mathrm{m}$ ) i Cr (wielkość ziarna $50 \mu \mathrm{m}$ ) o zmiennym składzie (rys. 1). Założony udział objętościowy

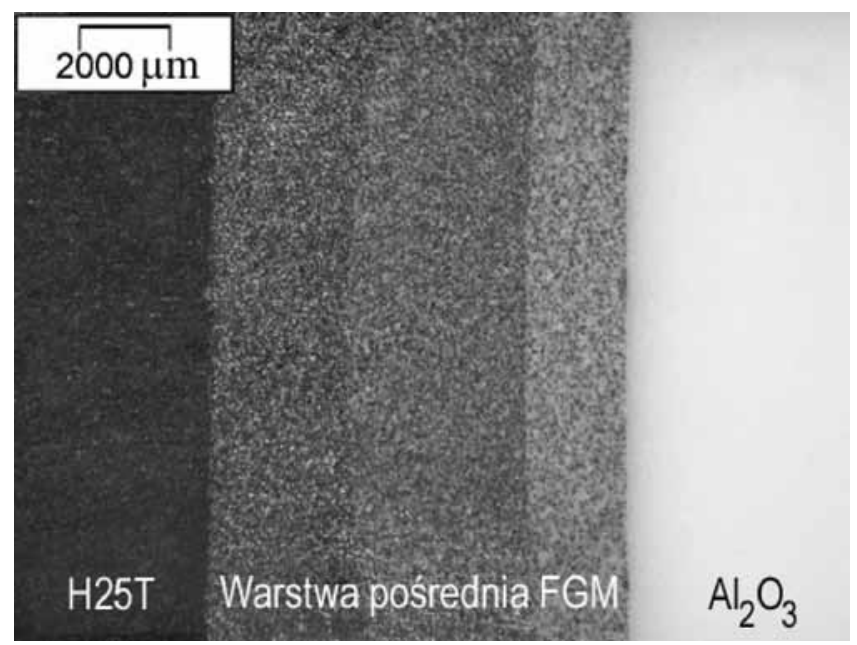

Rys. 1. Złącze $\mathrm{Al}_{2} \mathrm{O}_{3}-\mathrm{H} 25 \mathrm{~T} z$ warstwą pośrednią $\mathrm{FGM}$ Fig. 1. $\mathrm{Al}_{2} \mathrm{O}_{3}-\mathrm{H} 25 \mathrm{~T}$ joint with $\mathrm{FGM}$ intermediate layer 


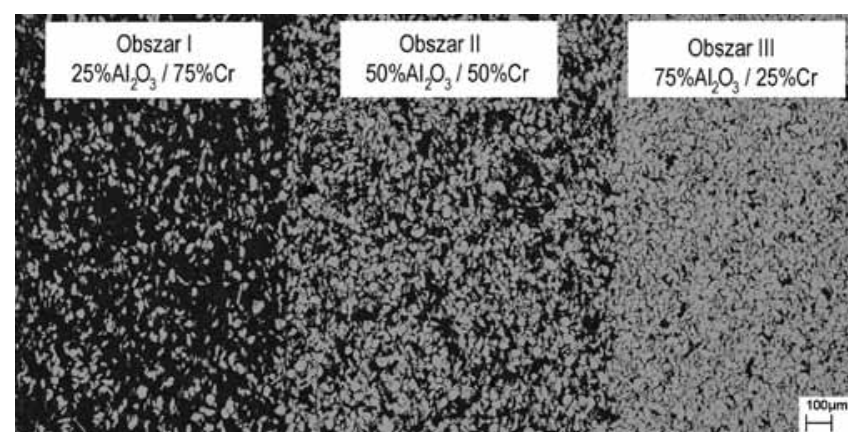

Rys. 2. Warstwa pośrednia $\mathrm{Al}_{2} \mathrm{O}_{3}-\mathrm{Cr}$

Fig. 2. $\mathrm{Al}_{2} \mathrm{O}_{3}-\mathrm{Cr}$ intermediate layer

w poszczególnych obszarach warstwy pośredniej (rys. 2) wynosit:

obszar I $\quad-25 \% \mathrm{Al}_{2} \mathrm{O}_{3} / 75 \% \mathrm{Cr}$

obszar II $\quad-50 \% \mathrm{Al}_{2} \mathrm{O}_{3} / 50 \% \mathrm{Cr}$

obszar III $\quad-75 \% \mathrm{Al}_{2} \mathrm{O}_{3} / 25 \% \mathrm{Cr}$

Szczegółowy opis wytworzenia badanej warstwy oraz parametry spajania złącza przedstawiono w [1].

Pomiar wymiaru fraktalnego wykonano na wybranych obrazach pochodzących z poszczególnych obszarów warstwy pośredniej. Obrazy cyfrowe struktur o wymiarach $512 \times 512$ pikseli poddano obróbce komputerowej, wykorzystując programy Image Tools i Image J. Zamieszczone w pracy wyniki pomiaru wymiaru fraktalnego oparto na liniowej modyfikacji fraktalnego wymiaru pudełkowego (BCD - box counting dimension), umożliwiającej dokładne skanowanie analizowanej struktury. Zastosowana metoda określania wymiaru fraktalnego została przedstawiona w [2]. Obliczenia wartości wymiaru fraktalnego przeprowadzono, wykorzystując program Skaner Wymiaru Fraktalnego (SWF), opracowany w Zakładzie Inżynierii Spajania Politechniki Warszawskiej. W ramach analizy obrazu oraz analizy fraktalnej określono zawartość $\mathrm{Al}_{2} \mathrm{O}_{3}$ $\mathrm{w}$ analizowanych strukturach oraz wymiar fraktalny liniowy $D, w$ dwóch prostopadłych do siebie kierunkach skanowania: poziomym - X i pionowym - Y.

\section{Struktura warstwy pośredniej i jej obrazy binarne}

W celu określenia wymiaru fraktalnego konieczne było przeprowadzenie obróbki komputerowej obrazów struktur, w wyniku której otrzymano obrazy binarne. $\mathrm{Na}$ rysunku 3 przedstawiono obrazy poddanych analizie struktur warstwy pośredniej złącza $\mathrm{Al}_{2} \mathrm{O}_{3}-\mathrm{H} 25 \mathrm{~T}$ oraz ich postać binarną. Wykonane pomiary wymiaru fraktalnego dotyczą $\mathrm{Al}_{2} \mathrm{O}_{3}$. Z tego względu oraz wymagań stawianych przez program SWF, na przedstawionych obrazach binarnych ceramika korundowa $\mathrm{Al}_{2} \mathrm{O}_{3}$ reprezentowana jest przez czarne piksele, a chrom przez białe.
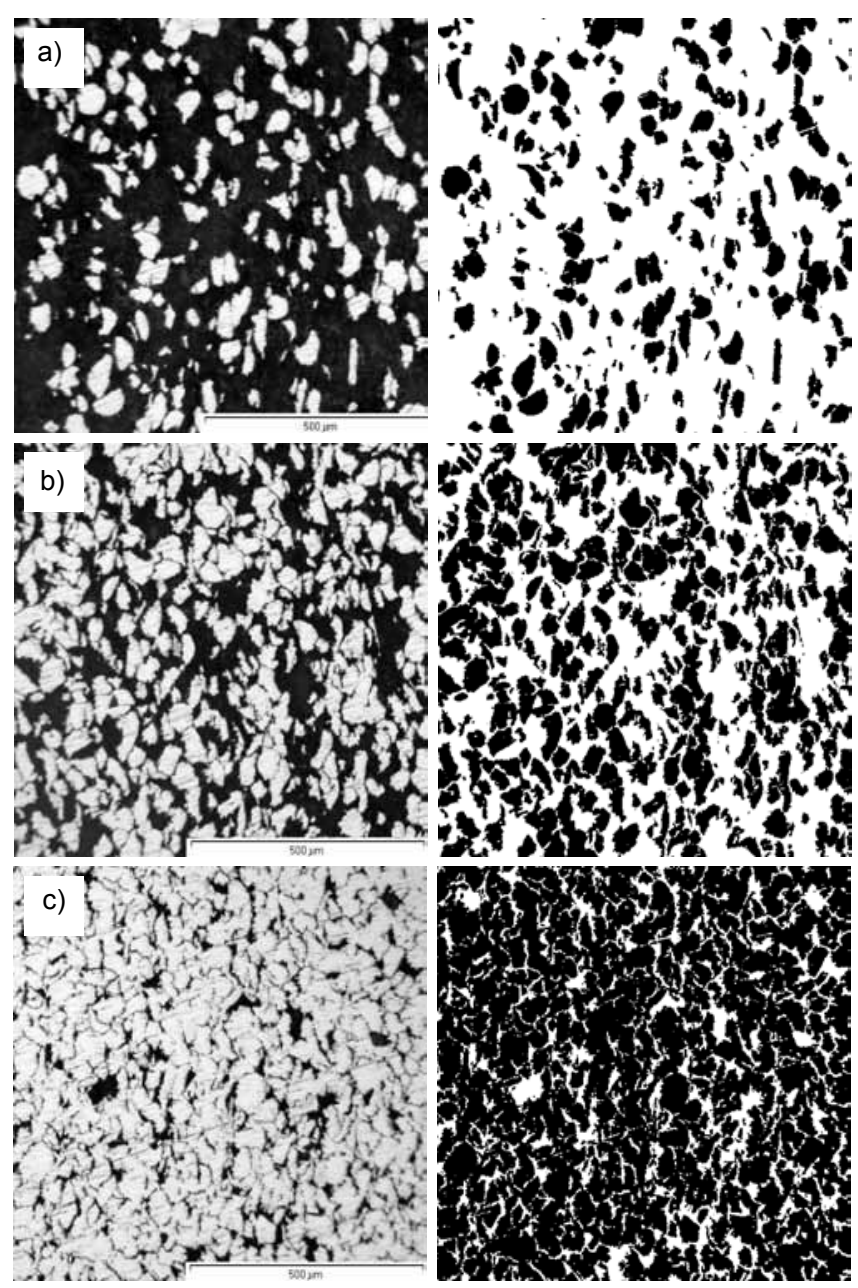

Rys. 3. Obrazy analizowanych struktur warstwy pośredniej złącza $\mathrm{Al}_{2} \mathrm{O}_{3}-\mathrm{H} 25 \mathrm{~T} \mathrm{i}$ ich wersje binarne: a) struktura $\mathrm{z}$ obszaru I, b) struktura z obszaru II, c) struktura z obszaru III

Fig. 3. Analysed structures of intermediate layer in $\mathrm{Al}_{2} \mathrm{O}_{3}-\mathrm{H} 25 \mathrm{~T}$ joint with binary view: a) structure of area I, b) structure of area II, c) structure of area III

\section{Rozkład $\mathrm{Al}_{2} \mathrm{O}_{3}$ na przekrojach poprzecznych warstwy pośredniej}

Wykorzystując komputerową analizę obrazu (program Image Tools) oraz obrazy binarne struktur, określono zawartość $\mathrm{Al}_{2} \mathrm{O}_{3}$. Wyniki pomiarów przedstawiono $w$ tablicy $I$.

W celu rozszerzenia przedstawionych $w$ tablicy I wyników pomiarów wykonano również pomiary zawartości $\mathrm{Al}_{2} \mathrm{O}_{3}$ wzdłuż każdej linii pomiarowej skanującej analizowany obraz $\mathrm{w}$ poziomie (kierunek skanowania $-\mathrm{X}$ ). Wykresy zmian zawartości $\mathrm{Al}_{2} \mathrm{O}_{3}$ dla obrazów binarnych analizowanych struktur przedstawiono na rysunku 4.

Tablica I. Zawartość $\mathrm{Al}_{2} \mathrm{O}_{3}$ w badanych strukturach warstwy pośredniej Table I. $\mathrm{Al}_{2} \mathrm{O}_{3}$ content in analysed structures of intermediate layer

\begin{tabular}{|c|c|c|c|}
\hline $\begin{array}{c}\text { Obszar warstwy } \\
\text { pośredniej }\end{array}$ & $\begin{array}{c}\mathrm{I}-25 \% \mathrm{Al}_{2} \mathrm{O}_{3} / \\
75 \% \mathrm{Cr}^{\prime}\end{array}$ & $\begin{array}{c}\mathrm{II}-50 \% \mathrm{Al}_{2} \mathrm{O}_{3} / \\
50 \% \mathrm{Cr}\end{array}$ & $\begin{array}{c}\mathrm{III}-75 \% \mathrm{Al}_{2} \mathrm{O}_{3} / \\
25 \% \mathrm{Cr}_{3}\end{array}$ \\
\hline $\begin{array}{c}\text { Zawartość } \\
\mathrm{Al}_{2} \mathrm{O}_{3}, \%\end{array}$ & 24,76 & 49,57 & 77,29 \\
\hline
\end{tabular}




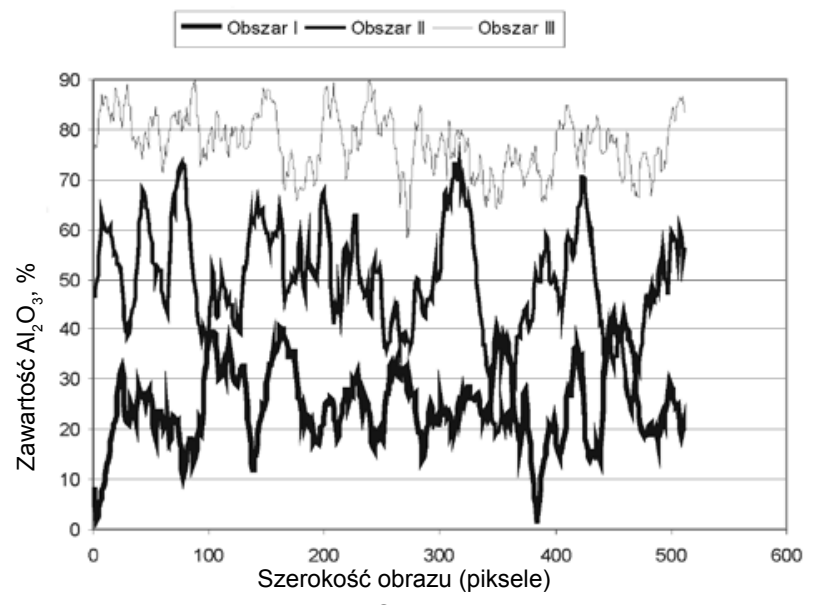

Rys. 4. Zmiany zawartości $\mathrm{Al}_{2} \mathrm{O}_{3}$ w analizowanych obszarach warstwy pośredniej złącza $\mathrm{Al}_{2} \mathrm{O}_{3}-\mathrm{H} 25 \mathrm{~T}$

Fig. 4. $\mathrm{Al}_{2} \mathrm{O}_{3}$ content changes in analysed areas of intermediate layer in $\mathrm{Al}_{2} \mathrm{O}_{3}-\mathrm{H} 25 \mathrm{~T}$ joint

\section{Wymiar fraktalny badanych struktur}

Wymiar fraktalny określono w dwóch prostopadłych kierunkach, skanując obrazy binarne w poziomie i pionie. W tablicy II podano zbiorcze wyniki określania wymiaru fraktalnego dla analizowanych struktur warstwy pośredniej, a na rysunku 5 przedstawiono wykresy

a)
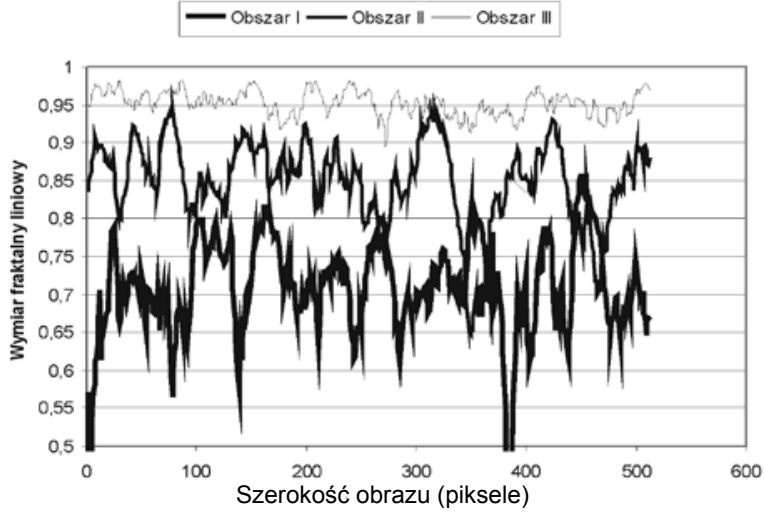

b)

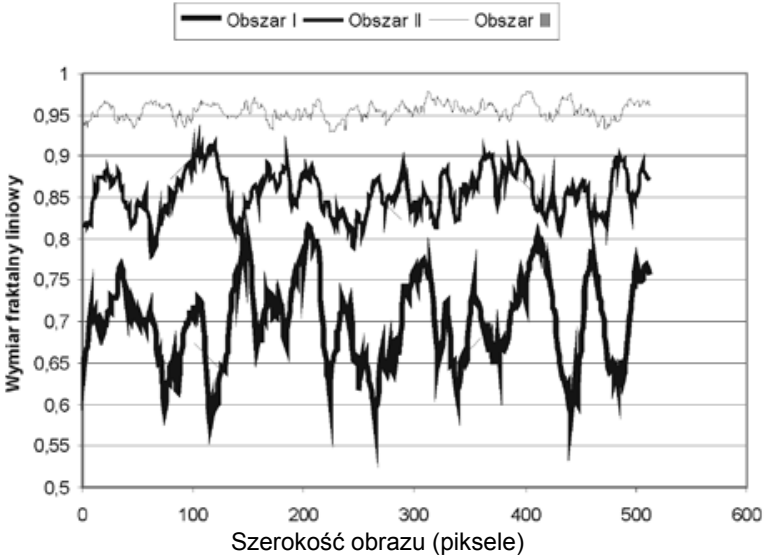

Rys. 5. Wymiar fraktalny $D_{\text {, }}$ analizowanych struktur warstwy pośredniej złącza $\mathrm{Al}_{2} \mathrm{O}_{3}-\mathrm{H} 25 \mathrm{~T}$ : a) kierunek skanowania $\mathrm{X}$, b) kierunek skanowania $Y$

Fig. 5. The fractal dimension $\left(D_{1}\right)$ of analysed structures of intermediate layer in $\mathrm{Al}_{2} \mathrm{O}_{3}-\mathrm{H} 25 \mathrm{~T}$ joint: a) scanning direction $\mathrm{X}$, b) scanning direction $Y^{2}$
Tablica II. Wymiar fraktalny analizowanych obszarów

Table II. The fractal dimension of analysed padding welds

\begin{tabular}{|c|c|c|}
\hline \multirow{2}{*}{$\begin{array}{c}\text { Obszar } \\
\text { warstwy } \\
\text { pośredniej }\end{array}$} & $\begin{array}{l}\text { Wymiar fraktalny } \\
D_{1 \text { min }} / D_{1 \text { śred }} / D_{1 \text { maks }}\end{array}$ & $\begin{array}{l}\text { Wymiar fraktalny } \\
D_{I_{\text {min }}} / D_{1 \text { śred }} / D_{1 \text { maks }}\end{array}$ \\
\hline & $\begin{array}{c}\text { Zakres wymiaru fraktalnego } \\
D_{1 \text { maks }}-D_{1 \text { min }} \\
\text { (skanowanie w poziomie } \\
\text { - kierunek } X\end{array}$ & $\begin{array}{c}\text { Zakres wymiaru fraktalnego } \\
D_{1 \text { maks }}-D_{1 \text { min }} \\
\text { (skanowanie w pionie } \\
\text { - kierunek } Y \text { ) }\end{array}$ \\
\hline \multirow{2}{*}{ I } & $0,2061 / 0,7082 / 0,8564$ & $0,5788 / 0,6995 / 0,8153$ \\
\hline & 0,6503 & 0,2365 \\
\hline \multirow{2}{*}{ II } & $0,6480 / 0,8485 / 0,9415$ & 0,7784 / 0,8562 / 0,9155 \\
\hline & 0,2935 & 0,1371 \\
\hline \multirow{2}{*}{ III } & 0,8935 / 0,9521 / 0,9825 & 0,9288 / 0,9547 / 0,9782 \\
\hline & 0,0890 & 0,0494 \\
\hline
\end{tabular}

a)
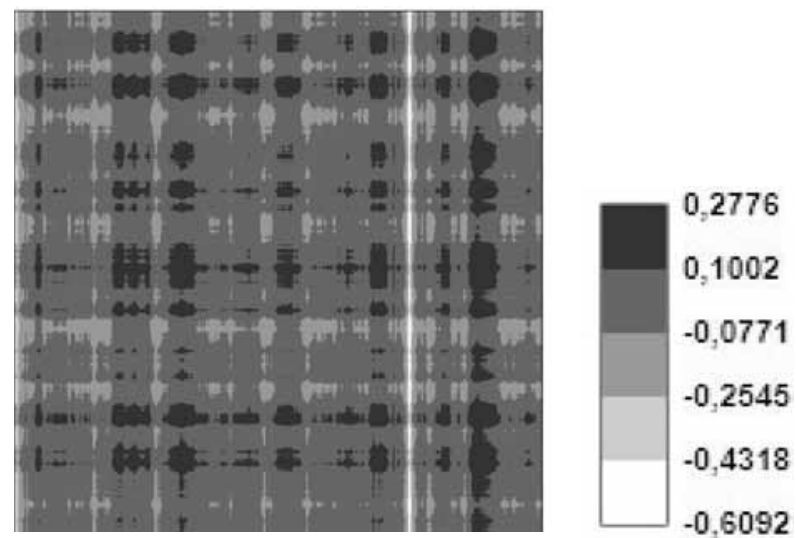

b)
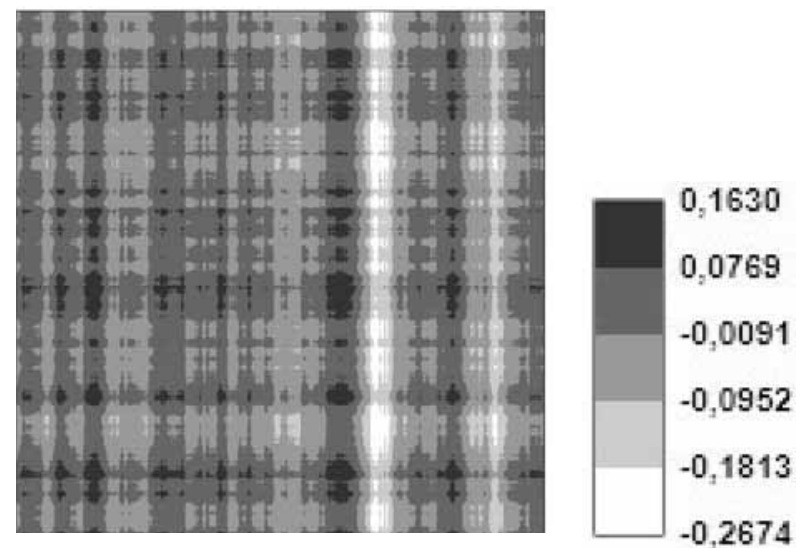

c)
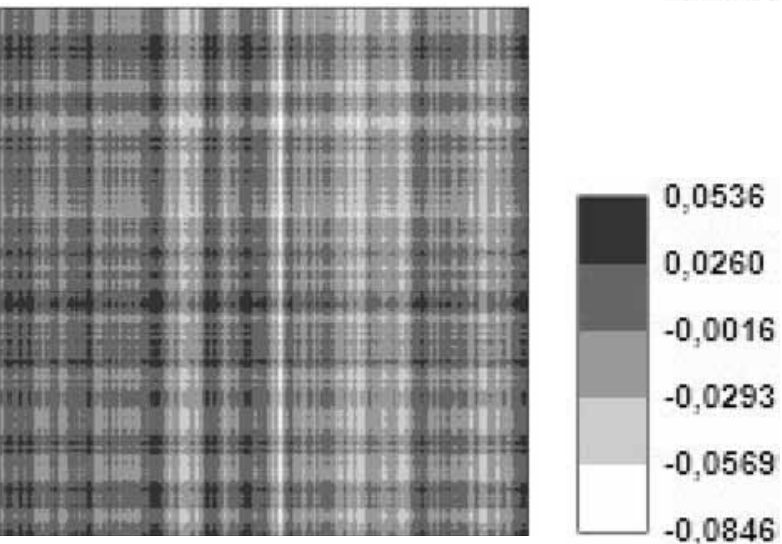

Rys. 6. Anizotropia wymiaru fraktalnego $\left(D_{I X}-D_{I Y}\right)$ badanych obszarów: a) obszar I, b) obszar II, c) obszar III

Fig. 6. The fractal dimension $\left(D_{I X}-D_{I Y}\right)$ anisotropy of analysed areas: a) area I, b) area II, c) area III 
- Gradientowa warstwa pośrednia -

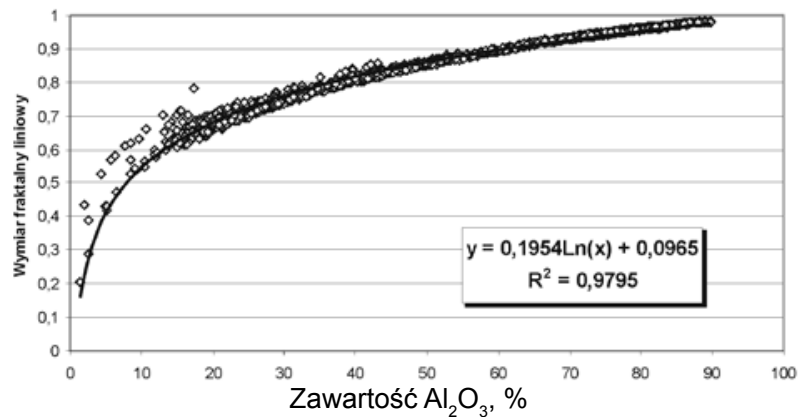

Rys. 7. Zależność wymiaru fraktalnego $\mathrm{D}_{1}$ od zawartości $\mathrm{Al}_{2} \mathrm{O}_{3}$ w strukturze

Fig. 7. The function of fractal dimension $\mathrm{D}_{1}$ on $\mathrm{Al}_{2} \mathrm{O}_{3}$ content in structure obrazujące zmiany wymiaru fraktalnego dla badanych struktur. W celu zwiększenia czytelności wykresów, na rysunku 5 a pominięto wartości wymiaru fraktalnego mniejsze od 0,5.

Uzupełnieniem wykonanych pomiarów są wykresy przedstawiające różnice wartości wymiarów fraktalnych $D_{I X}-D_{I Y}$ (anizotropię wymiaru fraktalnego dla kierunków skanowania X i Y) w poszczególnych punktach obrazów binarnych badanych obszarów warstwy pośredniej, przedstawione na rysunku 6.

Z zasady określania wymiaru fraktalnego wynika, że im większy udział analizowanego składnika w strukturze, tym większa wartość wymiaru fraktalnego. Na rysunku 7 przedstawiono zależność wymiaru fraktalnego od zawartości $\mathrm{Al}_{2} \mathrm{O}_{3}$ w strukturze warstwy pośredniej.

\section{Podsumowanie}

Przedstawione wyniki pomiarów zawartości $\mathrm{Al}_{2} \mathrm{O}_{3}$ w poszczególnych obszarach struktury warstwy pośredniej (tabl. I) wykazały zgodność z założonym udziałem objętościowymi i potwierdziły prawidłowość przyjętej technologii jej wytwarzania. Pomiary rozkładu $\mathrm{Al}_{2} \mathrm{O}_{3}$ wzdłuż każdej linii pomiarowej, wykonane dla kierunku skanowania $X$, wykazały lokalne różnice udziału $\mathrm{Al}_{2} \mathrm{O}_{3}$, bezpośrednio związane $\mathrm{z}$ jego rozkładem powierzchniowym w badanym obszarze (rys. 4). Największe różnice występują w obszarze I, a najmniejsze w obszarze III gradientowej warstwy pośredniej.

Pomiary wymiaru fraktalnego wykazały, iż najniższymi wartościami wymiaru fraktalnego i największym zakresem jego zmienności charakteryzował się obszar I, natomiast wartościami najwyższymi i najmniejszym zakresem zmian obszar III (tabl. II, rys. 5). Jednocześnie stwierdzono większe zakresy zmian wymiaru fraktalnego dla kierunku skanowania $X$ (maks. 0,6503 dla obszaru I) niż dla kierunku skanowania Y (maks. 0,2365 dla obszaru I). Różnice między wartościami średnimi wymiaru fraktalnego obliczonymi dla prostopadłych kierunków skanowania i odpowiadających sobie obszarów są stosunkowo niewielkie (poniżej 0,009). Zakres zmienności wymiaru ulega zawężeniu wraz ze wzrostem udziału $\mathrm{Al}_{2} \mathrm{O}_{3} \mathrm{w}$ badanej strukturze.

Najmniejszą anizotropię wymiaru fraktalnego stwierdzono dla obszaru III - różnica $D_{I X}-D_{I Y}$ wartości wymiaru fraktalnego nie przekroczyła 0,0846 (dla obszarów I i Il odpowiednio 0,6092 i 0,2674).

Analiza otrzymanych wyników pomiarów pozwoliła na określenie zależności między wymiarem fraktalnym $\mathrm{D}_{1}$ a zawartością $\mathrm{Al}_{2} \mathrm{O}_{3}$.

\section{Literatura}

[1] Grześ J., Pietrzak K.: Spajanie materiałów z wykorzystaniem nanokompozytowych warstw z gradientem składu. Archiwum Nauki o Materiałach, t. 25, $\mathrm{nr}$ 4/2003, s. 643-655.
[2] Grześ J.: Wymiar fraktalny wybranych struktur złącza spawanego ze stali $\mathrm{H} 17$, Prace Naukowe - Mechanika z. 229, WPW, Warszawa 2009. 